\title{
General Theory of Inflammation. Concise Summary of Basic Principles
}

\author{
Virgil I Stenberg* \\ Chester Fritz Distinguished Professor Emeritus, University of North Dakota, USA
}

*Corresponding author: Virgil I Stenberg, Chester Fritz Distinguished Professor Emeritus, University of North Dakota, 2579 Movil

Bay Lane NE, Bemidji, MN 56601, USA

\begin{tabular}{|c|c|}
\hline ARTICLE INFO & ABSTRACT \\
\hline Received: 蔧 January 20, 2020 & Keywords: Chronic Inflammation; Hydrocortisone; Inflammation Cause; Inflammation \\
\hline Published: 蔧 January 29, 2020 & Solution; Patient Self-Administration of Hydrocortisone; Microdose Therapy \\
\hline
\end{tabular}

Citation: Virgil I Stenberg. General Theory of Inflammation. Concise Summary of Basic Principles. Biomed J Sci \& Tech Res 25(1)2020. BJSTR. MS.ID.004142.

\section{Mini Review}

\section{Claim}

Patient self-administration of hydrocortisone with stress management promises to safely eliminate chronic inflammation from within all diseases of inflammation.

\section{Base Concepts}

Chronic inflammation is a disease unto itself for when active inflammation within the diseases of inflammation is completely arrested, symptoms disappear to only leave behind permanent damage such as destroyed joints [1]. Chronic inflammation is a house with many rooms. When long-term, destructive inflammation is localized, differing symptom sets are manifested depending on location. If inflammation resides in the heart, it is carditis; in the muscles, myositis; in the lungs, asthma; and in the brain, Parkinson's disease, dementia, or multiple sclerosis. When long-term, destructive inflammation exists within multiple body areas simultaneously, the resultant symptoms are composites with diagnoses such as rheumatoid arthritis, osteoarthritis, and fibromyalgia.

\section{Cause of Chronic Inflammation}

The cause of long-term, destructive inflammation is a defective inflammation control system within the body [2]. When defective, short-term, beneficial inflammation evolves into long-term, destructive inflammation. The inflammation control system is the hyopthalamic-pituitary-adrenal (HPA) axis. Upon activation by a stress, this axis creates a time-delayed, 6 -fold+ increased concentration hydrocortisone surge in the blood that terminates the activating, short-term, beneficial inflammation at its due time. As the hydrocortisone pulse of the HPA axis weakens because of age, injury, and/or heredity, short- term, beneficial inflammation evolves into long-term, destructive inflammation. As adrenal hydrocortisone production deteriorates further to being unable to sustain the blood concentration required to maintain homeostasis, both diseases of inflammation and Addison's disease threaten. Hydrocortisone, the inflammation-arresting agent of the inflammation control system, is the only body substance produced in adequate amounts capable of terminating inflammation. As a hormone, it can have no side effects when within its physiological concentrations in the blood. However, when administered to attain pharmacological concentrations in the blood for long periods, overdose hydrocortisone adverse effects can and do occur.

\section{Solution to Chronic Inflammation}

The solution to long-term, destructive inflammation is manually restoring the weakening hydrocortisone surge of the HPA axis to its optimum size [3]. Patient self-administration of hydrocortisone, the Addison's disease treatment recommended 
by the United States Food and Drug Aministration, is appropriate for restoring the hydrocortisone surge. Only patients know when the surge needing restoration occurs, that is, during bad days when short- term, beneficial inflammation is evolving into longterm, destructive inflammation. An initial induction period of daily hydrocortisone is necessary for patients to use self-administration of hydrocortisone effectively. This period enables patients to distinguish bad days when supplemental hydrocortisone is to be ingested from good days. A 3-week induction period of using daily pharmacologic hydrocortisone dosages related to body weight, sex, disease intensity, and age reduces severe daily symptoms to where cycling between bad and good days occurs.

For optimum success of patient self-administration of hydrocortisone, patients must be taught to minimize stresses that cause and exacerbate inflammation. Stresses as allergies [4], injuries, infections [5], and emotional traumas can be minimized by standard methodologies. Food allergies, over exercise, and infections more frequently counteract the anti-inflammatory effect of hydrocortisone administration to result in a less than optimum response. After induction period implementation and stress minimization, patients must be taught the implementation principles of hydrocortisone self-administration to maintain the inflammation control achieved during the induction period together with the safe limits of monthly hydrocortisone use to avoid hydrocortisone overdose effects [6].

\section{The Ultimate Test}

When patient self-administration of hydrocortisone with stress management was applied to 2,428 patients with 38 chronic inflammation diseases, symptom control exceeded standard treatment efficacies two-fold [1]. The treatment efficacies and response rates were the same within experimental error for the diseases of the study. One of 6 lost most or all symptoms in one day, 4 of 6 more lost the symptoms within 3 weeks, and the remaining 1 of 6 failed to respond to hydrocortisone. When patients used hydrocortisone tablets for pulse restoration on the bad days and not on the good days, so little hydrocortisone was ingested that overdose adverse effects were avoided. Only the missing hydrocortisone was replaced. The average daily consumption of hydrocortisone using patient self-administration of hydrocortisone was $12 \mathrm{mg}$ per day. This is less than the minimum $15 \mathrm{mg}$ daily hydrocortisone use that causes overdose symptoms in the most sensitive patients [6]. Consequently, patient self-administration of hydrocortisone with stress management was shortened to microdose therapy since patient's average using less hydrocortisone per day than the 20 to $52 \mathrm{mg}$ per day dose range of low-dose hydrocortisone. The hydrocortisone induction period should be repeated at 6-month intervals to arrest long-term, invisible-nevertheless-destructive, inflammation.

\section{Acknowledgement}

Microdose therapy was created to solve Helen's intractable rheumatoid arthritis. In 1984, she became asymptomatic using the therapy and remained as such with no significant adverse reactions until her passing in 2017. Her story is portrayed in the 1996 book entitled Arthritis. The Simple Solution available from Amazon.

\section{References}

1. Irwin JB, Baldwin AL, Stenberg VI (2019) General Theory of Inflammation: patient self- administration of hydrocortisone safely achieves superior control of hydrocortisone-responding disorders by matching dosage with symptom intensity. J Inflam Res 12: 161-166.

2. Stenberg VI, Bouley MG, Katz BM, Lee KJ, Parmar SS (1990) Negative endocrine control system for inflammation in rats. Agents Actions 29(34): 189-195.

3. Stenberg VI, Fiechtner JJ, Rice JR, Miller DR, Johnson LK (1992) Endocrine control of inflammation: rheumatoid arthritis double-blind, crossover clinical trial. Int J Clin Pharmacol Res 12(1): 11-18.

4. Panush RS, Stroud RM, Webster EM (1986) Food-induced (allergenic) arthritis. Inflammatory arthritis exacerbated by milk. Arthritis Rheum 29(2): 220-226.

5. Kloppenburg M, Breedveld FC, Terwiel JP, Mallee C, Dijkmans BA (1994) Minocycline in active rheumatoid arthritis. A double-blind, placebocontrolled trial. Arthritis Rheum 37(5): 629-636.

6. Slocumb CH, Polley HF, Ward LE (1957) Diagnosis, treatment and prevention of hypercortisonism in patients with rheumatoid arthritis. Proc Staff Meet Mayo Clin 32(9): 227-238.

\section{ISSN: 2574-1241}

DOI: $10.26717 /$ BJSTR.2020.25.004142

Virgil I Stenberg. Biomed J Sci \& Tech Res

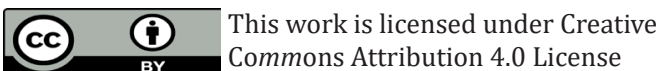

Submission Link: https://biomedres.us/submit-manuscript.php

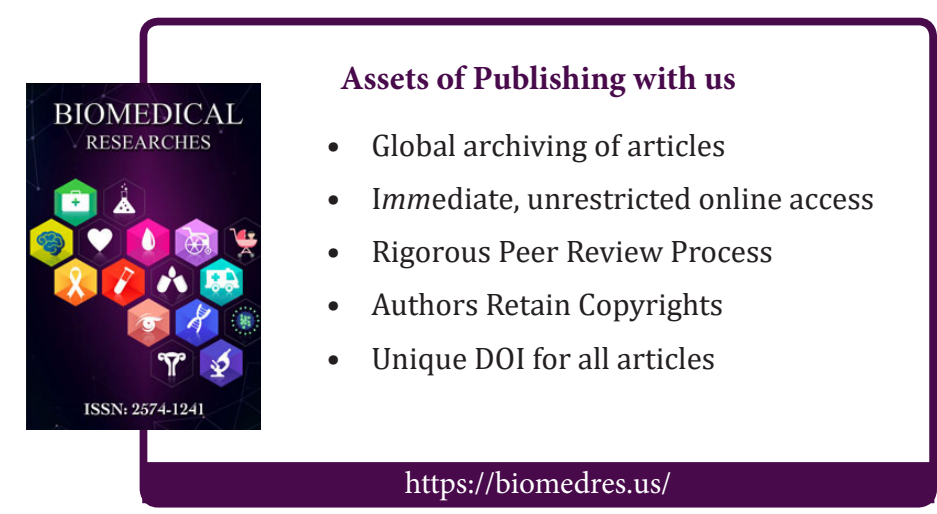

